\title{
Qualitative Analysis of Root Canal Treatments performed by Undergraduate Students: A Retrospective Study
}

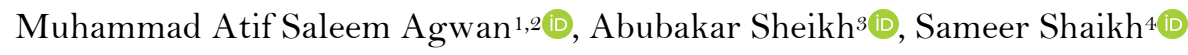

\begin{abstract}
'Department of Restorative Dentistry, College of Dentistry, Qassim University, Al Rass, Saudi Arabia.
${ }^{2}$ Department of Restorative Dentistry, Liaquat College of Medicine and Dentistry, Darul Sehat Hospital, Karachi, Pakistan.

${ }^{3}$ Department of Endodontics, Fatima Jinnah Dental College, Karachi, Pakistan.

${ }^{4}$ Division of Oral Diagnosis and Oral Medicine, Department of OMFS and Diagnostic Sciences, College of Dentistry, University of Hail, Ha'il, Saudi Arabia.
\end{abstract}

Correspondence: Dr. Muhammad Atif Saleem Agwan, Department of Restorative Dentistry, College of Dentistry in AlRass, Qassim University, Alshunanah Street, 52719, Ar Rass, ALQassim, KSA. E-mail: dratifagwan@yahoo.com

Academic Editor: Alessandro Leite Cavalcanti

Received: 22 December 2020 / Review: 15 May 2021 / Accepted: 21 June 2021

How to cite: Agwan MAS, Sheikh A, Shaikh S. Qualitative analysis of root canal treatments performed by undergraduate
students: a retrospective study. Pesqui Bras Odontopediatria Clín Integr. 2021; $21: e 0260$.
https://doi.org/10.1590/pboci.2021.156

\begin{abstract}
Objective: To analyze the technical quality of endodontic treatment carried out at the undergraduate dental clinics. Material and Methods: Random radiographic records of 92 patients' were selected who received endodontic treatment by the undergraduate students from June 2018 to July 2019. The quality of root canal filling was determined in relation to the adequate density, length, and taper. Statistical analysis was performed by using GraphPad (Prism 5), and to determine the association between different variables Chi-square test was used. Results: Adequate technical quality of canal obturation conducted by the undergraduate students was found in less than $65 \%$ of the cases. The frequency of adequate root canal taper was significantly greater in maxillary teeth $(75 \%)$ as compared to mandibular teeth (33\%); however, adequacy of acceptable density was found more in maxillary teeth $(62 \%)$ as compared to mandibular teeth $(55 \%)$. A statistically significant difference was seen in the quality of root canal fillings between anterior and posterior teeth $(\mathrm{p}=0.001)$. Conclusion: The root canal therapy performed by undergraduate students was less than optimum in terms of technical quality. Hence, it is suggested that the endodontic training courses delivered at pre-clinical and clinical levels for undergraduate students must be thoroughly revised.
\end{abstract}

Keywords: Students, Dental; Root Canal Therapy; Radiography, Dental; Root Canal Obturation. 


\section{Introduction}

To preserve teeth, root canal treatment is one of the primary forms of therapy provided as part of oral health care [1]. There are multiple steps for root canal treatment, including extirpation of pulp, canal preparation, and obturation [2]. Obturation is the final and the most important step in an endodontic treatment, which also determines the quality of root canal treatment radiographically [3].

It was observed that the standard and quality of root canal treatment performed by general dentists in various populations show a high percentile of inadequate root canal treatments [4,5]. One of the main reasons may be the adequate pre-clinical and clinical teachings at the level of undergraduates [6].

The procedure used to evaluate the quality of endodontic treatment is based on the sequence of steps from evaluating the clinical findings, radiographs and histological findings [7,8]. Radiographic analysis of obturation density, length of the canal filling from radiographic apex and tapered preparation of the root canal is evaluated to determine the quality of root canal treatment $[9,10]$.

The undergraduate trainees perform their clinical training mainly under the supervision of senior faculty members [11]. Many studies suggest that endodontic treatment performed by undergraduates is found to be of poor quality despite being under supervision $[9,12,13]$. An inferior root canal treatment may manifest into multiple complications, such as voids in the obturation, underfilling or overfilling, root perforation, furcal perforation, strip perforation, ledge, canal transportation, and instrument separation [14].

Dental students' lack of experience and misunderstanding of technical endodontic principles are attributed as the main causes of inferior root canal fillings [15]. In addition, a direct relationship between the quality of root canal fillings and the success of endodontic therapy helps to analyze students' clinical performance in providing quality endodontic treatment to patients [16].

This study aimed to analyze the technical quality of endodontic treatment carried out in the dental clinics of Liaquat College of Medicine and Dentistry, Karachi, by undergraduate students.

\section{Material and Methods}

Study Design and Sample

A retrospective cross-sectional study was designed to evaluate the quality of endodontic treatment among final-year undergraduate students. In this study, a random sample of 130 radiographs of patients were selected who had undergone endodontic treatment from June 2018 to July 2019. On analysis, 38 radiographs were excluded after careful observation and 92 radiographic samples with a total of 170 roots were selected.

\section{Data Collection}

Final-year students could treat endodontic cases, such as irreversible pulpitis with or without apical periodontitis and intentional endodontics of vital teeth. The radiographs selected for this analysis were treated endodontically by the final year students, with complete patient records including pre- and postoperative radiographs displaying the entire root and $2-3 \mathrm{~mm}$ of the periapical area. Patients less than 18 years of age, incomplete dental records, incomplete endodontic treatment, superimposition of anatomical structures, teeth without coronal restoration and poor quality radiographs were excluded from this study. The radiographs were analyzed by two senior faculty members with more than 10 years of clinical experience as an endodontist. The observers participated in calibration training before the radiographic analysis. Cohen's Kappa value was used to determine the inter-examiner reliability. The k-values were (0.80 and 0.82$)$, respectively. 


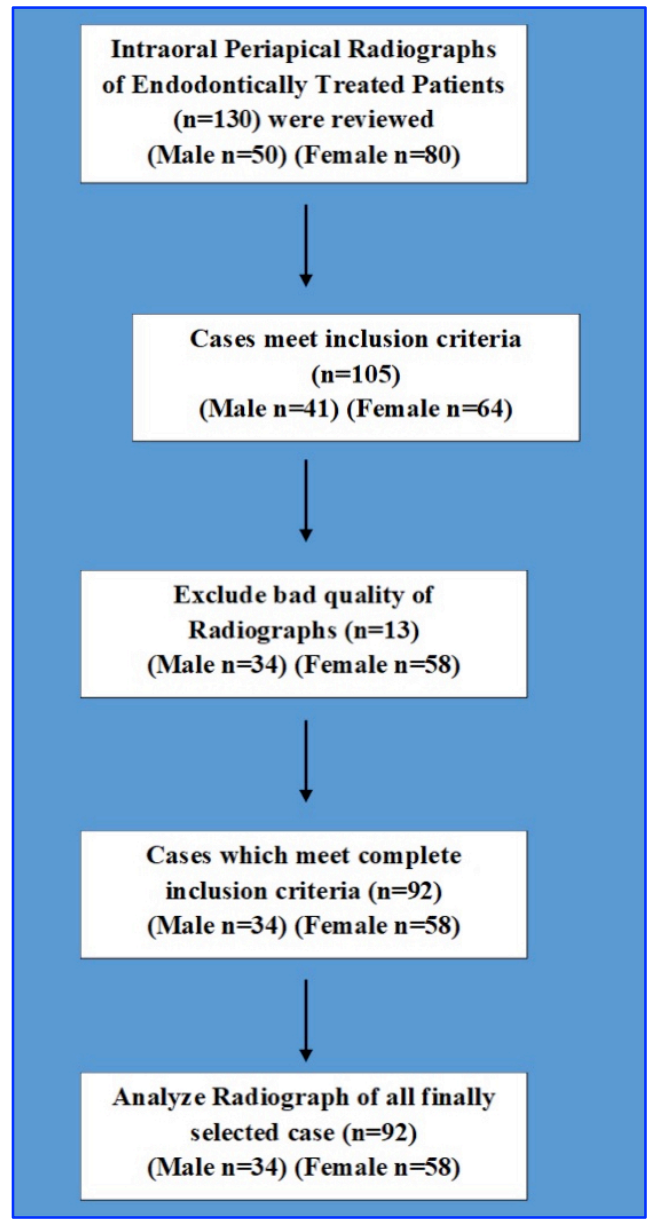

Figure 1. Study flow diagram of intraoral periapical radiograph of patients.

Teeth were classified as anterior (maxillary and mandibular incisors and canines) and posterior (maxillary and mandibular premolars and molars). Radiographs were used to evaluate the working length of the root canal. Using stainless steel K-files (Dentsply, Tulsa, OK, USA) of 0.02 tapering and 5.25\% sodium hypochlorite irrigation solution, a passive step-back technique was used in all the root canals. The root fillings were done with lateral condensation technique using gutta-percha and calcium hydroxide based sealer (Sealapex, Kerr Corporation, CA, USA).

The criteria for acceptance were appropriate length, adequate density and tapered shape with exclusion of iatrogenic errors as described by Khabbaz et al. [17] in Table 1. Other authors have also used the same criteria for judging the adequacy of root filling material.

Table 1. Criteria to assess root canal treatment quality.

\begin{tabular}{|c|c|c|}
\hline Variables & Criteria & Definitions \\
\hline \multirow[t]{3}{*}{ Length of Root Canal Filling } & Acceptable & Root filling ending $<2 \mathrm{~mm}$ short of radiographic apex. \\
\hline & Over & Root filling ending beyond the radiographic apex. \\
\hline & Under & Root filling ending $>2 \mathrm{~mm}$ short of radiographic apex. \\
\hline Density of Root Canal Filling & Acceptable & Uniform density of root filling without voids and canal space is not visible. \\
\hline \multirow{3}{*}{ Taper of Root Canal Filling } & Poor & $\begin{array}{l}\text { Not uniform density of root filling with clear presence of voids and canal } \\
\text { space is visible. }\end{array}$ \\
\hline & Acceptable & $\begin{array}{l}\text { Consistent taper from the coronal to the apical part of the filling, with } \\
\text { good reflect to canal shape. }\end{array}$ \\
\hline & Poor & Not consistent taper from the coronal to the apical part of the filling. \\
\hline
\end{tabular}


Adequate obturation means obturation must be the $2 \mathrm{~mm}$ to the radiographic apex, overfilled means filling ends beyond the radiographic apex, while underfilled means less than $2 \mathrm{~mm}$ to the radiographic apex. Adequate density is considered as the uniform filling throughout the root without spaces, inadequate density is considered as no uniformity in filling in the root. Finally, adequate taper is considered consistent tapering from the coronal portion of the root to the apex, and inadequate taper is considered non-consistent from coronal to apex. The endodontists used a magnifying lens $(2 \mathrm{x})$ and an $\mathrm{x}$-ray viewer individually to examine the radiograph and the results were finalized after consensus between them. A third endodontist was involved in case of disagreement and asked for a final analysis of the result.

\section{Data Analysis}

Statistical Analysis was performed by Prism 5 (GraphPad Software, San Diego, CA, USA). Data were expressed as frequencies and percentages. The Chi-square test was used for statistical evaluation of the results and the significance level was set at $\mathrm{p}<0.05$.

\section{Ethical Clearance}

This study was approved by the institutional review board of Liaquat College of Medicine and Dentistry (LCMD) with reference number (LCMD-REC/BDS/PO/let-18/00002).

\section{Results}

Periapical radiographs of 170 roots were evaluated in which 120 roots were from females and 50 roots were from males. The assessment revealed that in females, $34 \%$ roots were underfilled, $9 \%$ overfilled and adequacy of $57 \%$ in obturation was obtained, while in males, $32 \%$ roots were underfilled, $6 \%$ were overfilled and adequacy of $62 \%$ in obturation was found (Table 2 ).

In assessing the tapering of the roots, $42 \%$ are adequate and $58 \%$ are inadequate, while in density, $55 \%$ are adequate and $45 \%$ are inadequate in the female participants. Among the male participants, $30 \%$ adequate tapering of the canal and $70 \%$ inadequate tapering of canal, while $68 \%$ adequate and $32 \%$ inadequate density was found (Table 2). Thus, there was a statistical significant difference between male and female patients according to the quality of the root fillings $(p=0.008)$.

Table 2. Comparison between male and female patients.

\begin{tabular}{|c|c|c|c|c|c|c|c|c|c|c|}
\hline Sex & Age & No of Pt & No of Root & $\begin{array}{l}\text { Underfilled } \\
\qquad \mathrm{N}(\%)\end{array}$ & $\begin{array}{l}\text { Overfilled } \\
\qquad \mathrm{N}(\%)\end{array}$ & $\begin{array}{c}\text { Adequate } \\
\qquad \mathrm{N}(\%)\end{array}$ & $\begin{array}{c}\text { Taper } \\
\text { Adequate } \\
\mathrm{N}(\%)\end{array}$ & $\begin{array}{c}\text { Taper } \\
\text { Inadequate } \\
\mathrm{N}(\%)\end{array}$ & $\begin{array}{c}\text { Density } \\
\text { Adequate } \\
\mathrm{N}(\%)\end{array}$ & $\begin{array}{c}\text { Density } \\
\text { Inadequate } \\
\mathrm{N}(\%)\end{array}$ \\
\hline Female & $25-68$ & 58 & 120 & $40(34.0)$ & $11(9.0)$ & $69(57.0)$ & $51(42.0)$ & $70(58.0)$ & $66(55.0)$ & $54(45.0)$ \\
\hline Male & $16-38$ & 34 & 50 & $16(32.00$ & $3(6.0)$ & $31(62.0)$ & $15(30.0)$ & $35(70.0)$ & $34(68.0)$ & $16(32.0)$ \\
\hline
\end{tabular}

Statistical significant difference between male and female patients $(\mathrm{p}<0.05)$.

In anterior-posterior assessment, anterior roots were 31 and posterior roots were 139. In anterior, $35 \%$ were under-filled, $10 \%$ were overfilled and $55 \%$ had adequate length of obturation while the tapering consistency was $52 \%$ adequate and $48 \%$ inadequate and in the uniformity of density, $65 \%$ were adequate and $35 \%$ were inadequate. In the posterior roots, $35 \%$ were under-filled, $8 \%$ were overfilled and $57 \%$ had adequate length of obturation while the tapering consistency was $40 \%$ adequate and $60 \%$ were inadequate and in the uniformity of density, $57 \%$ were adequate and $43 \%$ were inadequate (Table 3). There was a significant difference between anterior and posterior teeth according to the quality of the root fillings $(\mathrm{p}=0.001)$. 
Table 3. Comparison between anterior and posterior teeth.

\begin{tabular}{|c|c|c|c|c|c|c|c|c|c|}
\hline $\begin{array}{c}\text { Tooth } \\
\text { Location }\end{array}$ & No of Pt & Age & $\begin{array}{c}\text { Underfilled } \\
\qquad \mathrm{N}(\%)\end{array}$ & $\begin{array}{c}\text { Overfilled } \\
\qquad \mathrm{N}(\%)\end{array}$ & $\begin{array}{c}\text { Adequate } \\
\text { N (\%) }\end{array}$ & $\begin{array}{c}\text { Taper } \\
\text { Adequate } \\
\text { N (\%) }\end{array}$ & $\begin{array}{c}\text { Taper } \\
\text { Inadequate } \\
\mathrm{N}(\%)\end{array}$ & $\begin{array}{c}\text { Density } \\
\text { Adequate } \\
\mathrm{N}(\%)\end{array}$ & $\begin{array}{c}\text { Density } \\
\text { Inadequate } \\
\mathrm{N}(\%)\end{array}$ \\
\hline Anterior & 31 & $16-68$ & $11(35.0)$ & $3(10.0)$ & $17(55.0)$ & $16(52.0)$ & $15(48.0)$ & $20(65.0)$ & $11(35.0)$ \\
\hline Posterior & 139 & $16-45$ & $49(35.0)$ & $11(8.0)$ & $79(57.0)$ & $55(40.0)$ & $84(60.0)$ & $79(57.0)$ & $60(43.0)$ \\
\hline
\end{tabular}

Statistical significant difference between anterior and posterior teeth $(\mathrm{p}<0.05)$.

In the maxillary mandibular assessment, maxillary roots were 88 and mandibular roots were 82 . In the maxillary roots, $27 \%$ were under-filled, $16 \%$ were overfilled and $57 \%$ were of adequate length in obturation, while in tapering consistency, $75 \%$ were adequate and $25 \%$ were inadequate and in uniformity of density, $62 \%$ were adequate and $38 \%$ were inadequate. In the mandibular roots, $30 \%$ were under-filled, $11 \%$ were overfilled and $59 \%$ were adequate in length of obturation, while in tapering consistency, $33 \%$ were adequate and $67 \%$ were inadequate, and in uniformity of density, $55 \%$ were adequate and $45 \%$ were inadequate (Table 4 ). According to the quality of root filling, there was a statistical significant difference between maxillary and mandibular teeth $(\mathrm{p}=0.006)$.

Table 4. Comparison between maxillary and mandibular teeth.

\begin{tabular}{ccccccccc}
\hline $\begin{array}{c}\text { Tooth } \\
\text { Location }\end{array}$ & $\begin{array}{c}\text { No of } \\
\text { Root }\end{array}$ & $\begin{array}{c}\text { Underfilled } \\
\text { Overfilled }\end{array}$ & $\begin{array}{c}\text { Adequate } \\
\mathrm{N}(\%)\end{array}$ & $\begin{array}{c}\text { Taper } \\
\text { Adequate }\end{array}$ & $\begin{array}{c}\text { Taper } \\
\text { Inadequate }\end{array}$ & $\begin{array}{c}\text { Density } \\
\text { Adequate }\end{array}$ & $\begin{array}{c}\text { Density } \\
\text { Inadequate }\end{array}$ \\
\hline Maxillary & 88 & $24(27.0)$ & $14(16.0)$ & $50(57.0)$ & $66(75.0)$ & $22(25.0)$ & $55(62.0)$ & $33(38.0)$ \\
Mandibular & 82 & $25(30.0)$ & $9(11.0)$ & $48(59.0)$ & $27(33.0)$ & $55(67.0)$ & $45(55.0)$ & $37(45.0)$ \\
\hline
\end{tabular}

Statistical significant difference between maxillary and mandibular teeth $(\mathrm{p}<0.05)$.

Figure 2 illustrates some radiographic examples of the underfilled and overfilled canals (A and B, respectively), voids in the obturation $(\mathrm{C})$.

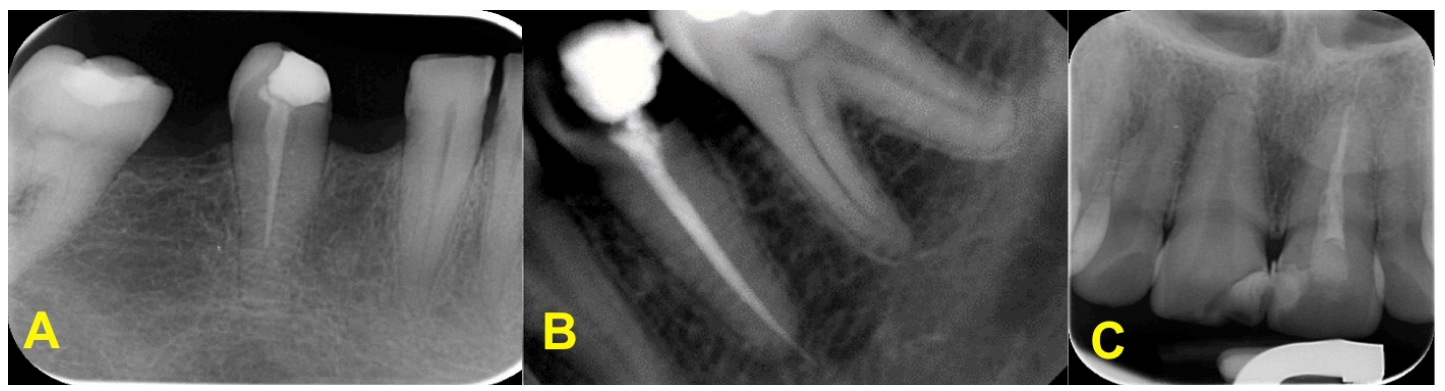

Figure 2. Canals filled short of radiographic apex. (A) Underfilled, (B) Overfilled, and (C) Inadequate Density.

\section{Discussion}

In our study, the result showed that females had $57 \%$ while males had $62 \%$ of the adequate obturation length. Our study's percentile was less as compared to other studies (73\% and $88.3 \%)$ [6,18,19]. This could be because undergraduates did not use an apex locator to measure the working length alongside the radiographs. Comparatively, in other countries, during root canal treatment apex locator is used side by side with a radiograph to determine the working [20-23].

The uniformity of density in females was $55 \%$, while in males it was $68 \%$. This difference in density uniformity was due to the gender-based morphological difference [7]. 
An additional criterion for assessing the potential obturation defect in a root canal treatment is the radiographic density [8]. Insufficient density may be followed by root canal failure due to micro-leakage of the root filling [23]. An insufficient density indicates improper condensation of gutta-percha in the root canal. The poor density of root fillings results in a higher prevalence of apical periodontitis [21,22,24]. In our study, the poor radiographic density of root canal was higher in percentage, which indicates a poor condensation of guttapercha during obturation. The final year students in Liaquat College of Medicine and Dentistry (LCMD) used cold lateral condensation as obturation technique.

Based on the guidelines provided by the European Society of Endodontology, a well-prepared root canal should be continuously tapered from the coronal part to the apex of the root [10]. Many studies have illustrated the significance of preserving the original shape of the root canal during and after the cleaning and shaping to acheive periapical healing in endodontic treatments [25]. An operator's inefficiency in preserving the root canal's original shape and establishing proper tapering canals can lead to a higher incidence of errors like forming perforations and ledges during endodontic procedures. In our study, $42 \%$ of teeth in females and $30 \%$ in males were observed to have adequate taper shape of the root canals. These results showed a comparatively lower percentile in comparison to previous studies [1,16].

In anteroposterior assessment, the anterior teeth had 31 roots, in which $55 \%$ had adequate length of obturation, $52 \%$ tapering of canal and $65 \%$ of uniformity in density. In contrast, the posterior teeth had 139 roots, in which $57 \%$ have adequate length of obturation, $40 \%$ tapering of canal and $57 \%$ of density uniformity. This difference in percentile between the anterior and posterior roots was because posterior roots are more curved than anterior and the consistency of tapering is less adequate in posterior teeth than anterior teeth [13]. This finding is similar to other studies [26,27].

In maxillary and mandibular assessment, the maxillary teeth have 88 roots in which $57 \%$ were adequately obturated, $75 \%$ had consistent tapering canals and $62 \%$ had a uniform density of root fillings, while in the mandibular teeth ( 82 roots) in which $59 \%$ were adequately obturated, $33 \%$ had properly tapered canals and $55 \%$ had a uniform density of filling. The difference in the percentile between maxillary and mandibular roots is due to the morphological difference between them [24].

The methods used in this study to analyze the radiographs were adopted from previously conducted studies [18,28]. In some studies, assessing the quality of root canal treatment by radiographs was unacceptable as it could not impose conclusive results of root canal treatment failure, but other studies concluded that using radiographs for quality assessment was acceptable and consistent [8,13,24,25]. Furthermore, according to epidemiological studies, the other elements such as following aseptic techniques, quality of shaping canals, materials utilized, and treatment pattern, including intercanal medication administration, are prognostic factors [15,29].

To make better progress in the technical quality of endodontic treatments conducted by undergraduates, the curriculum of endodontics needs to be revised. In addition, the training duration of students performing endodontics at clinics and its clinical requirements need to be increased. Different studies suggested that due to unsatisfied quality of root canal treatment, the teachings at pre-clinical and clinical level need to be refined [30].

Practice of root canal treatment begins in the final year with initial training on extracted human teeth. Other studies have shown similar concerns about the duration of work in endodontic clinics is not enough to master this skill $[9,31,32]$. 
Elsayed et al. [33] reported a high rate of unacceptable root canal treatment done by undergraduate students because of lack in pre-clinical endodontics training. Other studies also support our finding by concluding that poor quality root canal treatment was found among undergraduates [11,34]. This suggested that the training course of undergraduates in endodontics has to be improved before stepping into clinical practice. New methods and gadgets must be included in curriculum to improve the quality of outcomes [35].

Some limitations can be observed regarding the data collected, mostly by existing records, which included the readability of handwriting on hospital files. In addition, students have sometimes forgotten to record a complete visit or omitted the tooth number on which the treatment procedure was performed. To evaluate the technical quality of the finished root treatment, two-dimensional radiographs (conventional digital intraoral) were employed. However, three-dimensional radiography (CBCT scan/cone beam) may have provided more accurate results.

\section{Conclusion}

The root canal therapy performed by undergraduate students was found to be less than optimum in terms of technical quality. Hence, it is suggested that the endodontic training courses need to be revised at the pre-clinical and clinical levels of undergraduate students.

\section{Authors' Contributions}

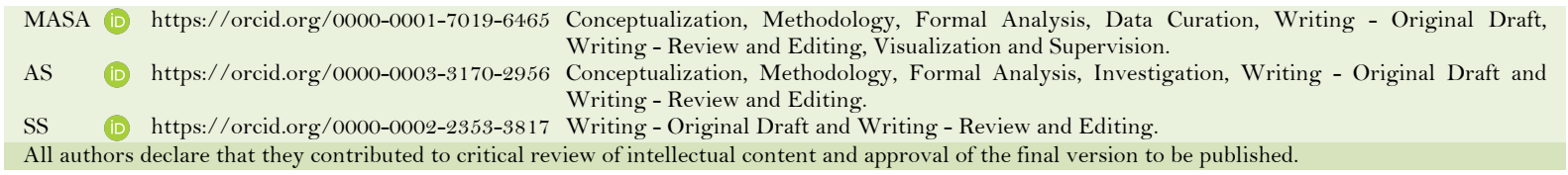

\section{Financial Support}

None.

\section{Conflict of Interest}

The authors declare no conflicts of interest.

\section{Data Availability}

The data used to support the findings of this study can be made available upon request to the corresponding author.

\section{References}

[1] Aliuddin AM, Ali JZ, Sheikh A, Rashid S, Ali M, Abdullah F. Radiographic quality of root canal filling performed by house officers at a teaching institute in karachi, pakistan. J Pak Dent Assoc 2019; 28(2):55-62. https://doi.org/10.25301/JPDA.282.55

[2] Levine M. Root-canal therapy: a means of treating oral pain and infection. Can Fam Physician 1988; 34:1357-65.

[3] Chugal NM, Clive JM, Spångberg LS. Endodontic infection: some biologic and treatment factors associated with outcome. Oral Surg Oral Med Oral Pathol Oral Radiol Endod 2003; 96(1):81-90. https://doi.org/10.1016/s1079-2 104(02)91703-8

[4] Jamani KD, Fayyad MA. A radiographic study of the prevalence of endodontically treated teeth and procedural errors of root canal filling. Odontostomatol Trop 2005; 28(111):29-33.

[5] Segura-Egea JJ, Jiménez-Pinzón A, Poyato-Ferrera M, Velasco-Ortega E, Ríos-Santos JV. Periapical status and quality of root fillings and coronal restorations in an adult Spanish population. Int Endod J 2004; 37(8):525-30. https://doi.org/10.1111/j.1365-2591.2004.00826.x

[6] Fayyaz A, Ehsan S, Waseem RF. Radiographic evaluation of endodontic treatment performed by undergraduate students and interns. J Pak Dent Assoc 2018; 27(3):115-19. https://doi.org/10.25301/JPDA.273.115 
[7] Weiger R, Hitzler S, Hermle G, Löst C. Periapical status, quality of root canal fillings and estimated endodontic treatment needs in an urban German population. Endod Dent Traumatol 1997; 13(2):69-74. https://doi.org/10.1111/j.1600-9657.1997.tboo013.x

[8] Boucher Y, Matossian L, Rilliard F, Machtou P. Radiographic evaluation of the prevalence and technical quality of root canal treatment in a French subpopulation. Int Endod J 2002; 35(3):229-38. https://doi.org/10.1046/j.1365-2591.2002.00469.x

[9] Barrieshi-Nusair KM, Al-Omari MA, Al-Hiyasat AS. Radiographic technical quality of root canal treatment performed by dental students at the Dental Teaching Center in Jordan. J Dent 2004; 32(4):301-7. https://doi.org/10.1016/j.jdent.2004.01.002

[10] Er O, Sagsen B, Maden M, Cinar S, Kahraman Y. Radiographic technical quality of root fillings performed by dental students in Turkey. Int Endod J 2006; 39(1 1):867-72. https://doi.org/10.1111/j.1365-2591.2006.01158.x

[11] Habib AA, Doumani MD, Nassani MZ, Shamsy E, Jto BS, ArwadI HA, et al. Radiographic assessment of the quality of root canal fillings performed by senior dental students. Eur Endod J 2018; 3(2):101-6. https://doi.org/10.14744/eej.2018.69775

[12] Galhotra V, Rai T, Kaur I. Assessment of quality of root canal fillings performed by undergraduate dental students. J Adv Med Dent Scie Res 2017; 5(1):153-7. https://doi.org/10.2 1276/jamdsr.2017.5.1.35

[13] Chakravarthy P, Moorthy J. Radiographic assessment of quality of root fillings performed by undergraduate students in a Malaysian Dental School. Saudi Endo J 2013; 3:77. https://doi.org/10.4103/1658-5984.118155

[14] AlRahabi MK. Evaluation of complications of root canal treatment performed by undergraduate dental students. Libyan J Med 2017; 12(1):1345582. https://doi.org/10.1080/19932820.2017.1345582

[15] Unal GC, Kececi AD, Kaya BU, Tac AG. Quality of root canal fillings performed by undergraduate dental students. Eur J Dent 2011; 5(3):324-30.

[16] Saatchi M, Mohammadi G, Vali Sichani A, Moshkforoush S. Technical quality of root canal treatment performed by undergraduate clinical students of Isfahan Dental School. Iran Endod J 2018; 13(1):88-93. https://doi.org/10.22037/iej.v13i1.18517

[17] Khabbaz MG, Protogerou E, Douka E. Radiographic quality of root fillings performed by undergraduate students. Int Endod J 2010; 43(6):499-508. https://doi.org/10.1111/j.1365-2591.2010.01706.x

[18] Smith CS, Setchell DJ, Harty FJ. Factors influencing the success of conventional root canal therapy--a five-year retrospective study. Int Endod J 1993; 26(6):321-33. https://doi.org/10.1111/j.1365-2591.1993.tbo0765.x

[19] Swartz DB, Skidmore AE, Griffin JA Jr. Twenty years of endodontic success and failure. J Endod 1983; 9(5):198-202. https://doi.org/10.1016/So099-2399(83)80092-2

[20] Peak JD, Hayes SJ, Bryant ST, Dummer PM. The outcome of root canal treatment. A retrospective study within the armed forces (Royal Air Force). Br Dent J 2001; 190(3):140-4. https://doi.org/10.1038/sj.bdj.4800907

[21] Alrahabi M, Younes HB. A cross-sectional study of the quality of root canal treatment in Al-Madinah AlMunawwarah. Saudi Endod J 2016; 6:31-5. https://doi.org/10.4103/1658-5984.172005

[22] Al-Nazhan SA, Alsaeed SA, Al-Attas HA, Dohaithem AJ, Al-Serhan MS, Al-Maflehi NS. Prevalence of apical periodontitis and quality of root canal treatment in an adult Saudi population. Saudi Med J 2017; 38(4):413-21. https://doi.org/10.15537/smj.2017.4.16409

[23] Alhablain EA, Sadaf D, Ahmad MZ, Alqanass BS. Quality of Root Canal Therapy (RCT) performed by the undergraduate students at the Qassim University, Kingdom of Saudi Arabia (KSA). Med Forum 2018; 29(6):80-4.

[24] Moussa-Badran S, Roy B, Bessart du Parc AS, Bruyant M, Lefevre B, Maurin JC. Technical quality of root fillings performed by dental students at the dental teaching centre in Reims, France. Int Endod J 2008; 41(8):679-84. https://doi.org/10.1111/j.1365-2591.2008.01417.x

[25] Martín-González J, Echevarría-Pérez M, Sánchez-Domínguez B, Tarilonte-Delgado ML, Castellanos-Cosano L, López-Frías FJ, et al. Influence of root canal instrumentation and obturation techniques on intra-operative pain during endodontic therapy. Med Oral Patol Oral Cir Bucal 2012; 17(5):e912-8, https://doi.org/10.4317/medoral.18234

[26] Hendi SS, Karkehabadi H, Eskandarloo A. Iatrogenic errors during root canal instrumentation performed by dental students. Iran Endod J 2018; 13(1):126-31. https://doi.org/10.22037/iej.v13i1.18507

[27] Vukadinov T, Blažić L, Kantardžić I, Lainović T. Technical quality of root fillings performed by undergraduate students: a radiographic study. Sci World J 2014; 2014:751274. https://doi.org/10.1155/2014/751274

[28] Almakrami AM, Alyami YA, Al Yami AM, Al Yami JM, Almakrami YH, Nalalhareth N, et al. Qualitative assessment of root canal treatment risk factors failures among patients at the specialist dental center in Najran: a clinical survey. J Int Med Dent 2008; 5(3):93-101. https://doi.org/10.18320/JIMD/201805.0393

[29] Shah N, Bansal N, Logani A. Recent advances in imaging technologies in dentistry. World J Radiol 2014; 6(10):794807. https://doi.org/10.4329/wjr.v6.i10.794

[30] Tchorz JP, Ganter PA, Woelber JP, Stampf S, Hellwig E, Altenburger MJ. Evaluation of an improved endodontic teaching model: do preclinical exercises have an influence on the technical quality of root canal treatments?. Int Endod J 2014; 47(5):410-5. https://doi.org/10.1111/iej.12162 
[31] Dummer PM. Comparison of undergraduate endodontic teaching programmes in the United Kingdom and in some dental schools in Europe and the United States. Int Endod J 1991; 24(4):169-77. https://doi.org/10.1111/j.1365-2591.1991.tbo0127.x

[32] Qualtrough AJE, Dummer PMH. Undergraduate endodontic teaching in the United Kingdom: An update. Int Endod J 1997; 30(4):234-39. https://doi.org/10.1046/j.1365-2591.1997.to1-1-00072.x

[33] Elsayed RO, Abu-Bakr NH, Ibrahim YE. Quality of root canal treatment performed by undergraduate dental students at the University of Khartoum, Sudan. Aust Endod J 2011; 37(2):56-60. https://doi.org/10.1111/j.1747-4477.2010.00273.x

[34] Al-Anesi MS, AlKhawlani MM, Alkheraif AA, Al-Basmi AA, Alhajj MN. An audit of root canal filling quality performed by undergraduate pre-clinical dental students, Yemen. BMC Med Educ 2019; 19(1):350. https://doi.org/10.1186/s12909-019-1798-1

[35] Kaplan T, Sezgin GP, Sönmez-Kaplan S. Dental students' perception of difficulties concerning root canal therapy: A survey study. Saudi Endod J 2020; 10:33-8. https://doi.org/10.4103/sej.sej_35_19 